\title{
Ruokohelven viljelyn riskit
}

Elina Virkkunen ${ }^{1)}$, Saara Nikkari ${ }^{2}$ ja Olli Reinikainen ${ }^{3)}$

${ }^{1)}$ MTT Sotkamo, Kipinäntie 16, 88600 Sotkamo, elina.virkkunen@mtt.fi

${ }^{2)}$ Helsingin yliopisto, Maataloustieteiden laitos, Latokartanonkaari 5, 00014 Helsingin yliopisto, saara.nikkari@helsinki.fi

${ }^{3)}$ Vapo Oy, PL 22, 40101 Jyväskylä, olli.reinikainen@vapo.fi

\section{Tiivistelmä}

Ruokohelpi (Phalaris arundinacea L.) on monivuotinen heinäkasvi, jota viljellään sekä rehuksi että energiaksi. Se kasvaa luonnonvaraisena pohjoisella pallonpuoliskolla. Suomessa sitä viljellään 16000 hehtaarin alalla lähinnä energiakäyttöön. Ruokohelpikasvusto on pitkäikäinen ja lisääntyy sekä suvullisesti siemenistä että suvuttomasti vahvan juurakon avulla. Ruokohelven leviämistä viljelyalueen ulkopuolelle ja viljelyn lopettamisen hankaluutta pidetään viljelyn riskeinä.

MTT Sotkamossa tutkittiin ruokohelven viljelyn lopettamisessa sekä ruokohelven leviämistä viljelylohkon ulkopuolelle osana Biokaasu ja peltoenergia Kainuussa -hanketta. Kokeita tehtiin ja havainnoitiin vuosina 2008 - 2011. Hanke rahoitettiin osittain Euroopan maaseudun kehittämisen maatalousrahastosta. Muita rahoittajia olivat Suomen valtio, Kainuun kunnat ja yksityiset yritykset, kuten Vapo Oy.

Ruokohelpikasvustoa hävitettäessä on käytettävä sekä kemiallista että mekaanista torjuntaa. Kasvustosta kannattaa ottaa ensin yksi tai kaksi rehusatoa ja ruiskuttaa kasvusto sen jälkeen syyskyntöä unohtamatta. Seuraavana vuonna yksivuotinen kevätvilja ja syyskyntö täydentävät ruiskutusta. Pelkkä mekaaninen torjunta, kyntö ja jyrsintä, ei hävitä ruokohelpeä täysin. Juolavehnä osoittautui kuitenkin mekaanisen torjunnan ruuduissa huomattavasti hankalammaksi rikkakasviksi kuin ruokohelpi. Ruokohelpeä ruiskutettiin myös tuleentuneesta ohrakasvustosta. Ruokohelpi näytti ensin hävinneen, mutta sitä ilmestyi alueelle seuraavana vuonna loppukesästä.

Kenttäkokeiden perusteella ruokohelpi ei leviä kasvullisesti viljelylohkon ulkopuolisille pelloille. Siemenistä leviäminen on vähäistä ja keskittyy muokatuille reuna-alueille. Hennot siementaimet eivät lähteneet kasvuun olemassa olevassa kasvustossa. Ruokohelpipellon vieressä viljeltiin ohraa ja nurmea ja siinä oli myös kesantolohko. Ruokohelven leviämisessä eri lohkoille ei ollut mainittavia eroja. Nurmen joukossa vähäinen ruokohelpi ei ollut muodostunut ongelmaksi, ja niitto rehuksi ilmeisesti hillitsi ruokohelven kasvua.

Heinäkuuhun ajoittunut Palaton-ruokohelven kukinta kesti Sotkamossa 14 päivää. Siitepölyn leviämistä ei havainnoitu tässä tutkimuksessa. Ruokohelven siitepölyn allergisoivaa vaikutusta voi verrata timoteihin tai rukiiseen.

\section{Asiasanat}

ruokohelpi, Phalaris arundinacea, viljelyn lopettaminen, ruokohelven leviäminen 


\section{Johdanto}

Ruokohelpi (Phalaris arundinacea L.) on monivuotinen heinäkasvi, jota viljellään sekä rehuksi että energiaksi. Se kasvaa luonnonvaraisena pohjoisella pallonpuoliskolla. Suomessa sitä viljellään 16000 hehtaarin alalla lähinnä energiakäyttöön (Tike 2011). Ruokohelpi tuottaa satoa ensimmäisen satovuoden jälkeen 6-8 tn ka/ha (Pahkala ym. 2005). Poltettavaksi viljeltävä ruokohelpi korjataan keväällä kuloheinänä, ja se poltetaan seoksena turpeen tai hakkeen kanssa.

Vapo Oy on tutkinut ja kokeillut ruokohelven viljelyä turvetuotannosta poistuneilla suopohjilla 1990-luvulta lähtien (Hakkarainen 1998). Viljelyala oli Suomessa korkeimmillaan vuonna 2007, jolloin ruokohelpeä kasvoi 19000 hehtaarin alalla (Tike 2007). Viljelyalan ennustettiin kasvavan yli 50000 hehtaariin vuoteen 2010 mennessä (Pahkala ym. 2009). Ala ei kuitenkaan ole kasvanut ennustetusti ja on ollut vuoden 2008 jälkeen laskusuunnassa. Viljelyn kannattavuus ei ole vastannut yksityisviljelijöiden odotuksia. Menekki voimalaitoksilla on kääntynyt laskuun, eivätkä laitokset ole olleet valmiita investoimaan ruokohelven käsittelyn vaatimiin laitteisiin. Vapo Oy on luopumassa osasta suoviljelyksiään, eikä tee tällä hetkellä viljelijöiden kanssa uusia viljelysopimuksia (Sironen 2011).

Ruokohelven viljelyn aloittaneita viljelijöitä on askarruttanut ruokohelven mahdollinen leviäminen viereisille peltolohkoille sekä sen jääminen rikkakasviksi pellolle viljelyn lopettamisen jälkeen. Myös siitepöly on nähty haittana ruokohelpipeltojen lähellä asuville ihmisille.

Monivuotisella kasvustolla on vahva juurakko, mutta se ulottuu korkeintaan $15 \mathrm{~cm}$ syvyyteen. Yksittäiset juuret voivat kasvaa yli metrin syvyyteen. (Pahkala ym. 2005) Ruokohelpikasvusto on pitkäikäinen ja se lisääntyy sekä suvullisesti siemenistä että suvuttomasti juurakon avulla. PohjoisAmerikassa ruokohelpeä pidetään suurena ongelmana, sillä se leviää tehokkaasti ja syrjäyttää luonnontilaisissa kosteikoissa muut kasvit (Apfelbaum \& Sams 1987).

Tämän tutkimuksen tarkoitus oli havainnoida eri menetelmien tehokkuutta ruokohelven viljelyn lopettamisessa sekä ruokohelven leviämistä viljelylohkon ulkopuolelle. Oletuksena oli, että tehokkain ruokohelven viljelyn lopetusmenetelmä on glyfosaattiruiskutus. Ruokohelven ei oletettu leviävän viljelmän ulkopuolelle varsinkaan, jos viereinen pelto kynnetään vuosittain. (Pahkala ym. 2005)

Tutkimukset sisältyivät kolmivuotiseen hankkeeseen Biokaasu ja peltoenergia Kainuussa. Hanke rahoitettiin osittain Euroopan maaseudun kehittämisen maatalousrahastosta. Muita rahoittajia olivat Suomen valtio, Kainuun kunnat ja yksityisrahoittajat, kuten Vapo Oy.

\section{Aineisto ja menetelmät \\ Ruokohelven hävittämiskoe}

Koe tehtiin vuonna 2005 perustetussa ruokohelpikasvustossa MTT Sotkamon tutkimusaseman pellolle. Pellon maalaji oli runsasmultainen hietamoreeni. Alueella tehtiin vuosina 2005 - 2008 ruokohelven perustamis- ja hivenlannoituskoe. Alueelta korjattu ruokohelven kevätsato oli vuonna 2008 keskimäärin $6590 \mathrm{~kg} \mathrm{ka/ha.} \mathrm{(Virkkunen} \mathrm{ym.} \mathrm{2010)}$

Oletuksena oli, että ruokohelpikasvuston hävittämiseen tarvitaan kemiallisen ja mekaanisen torjunnan yhdistelmä. Glyfosaattivalmiste oli Roundup Max (Tukes 2011 c), jota käytettiin suosituksen mukainen määrä 2,0 kg/ha. Valmisteessa on glyfosaattia $680 \mathrm{~g} / \mathrm{kg}$.

Pahkopuron alueella koeruutuja oli viisi, ja kunkin pinta-ala oli $100 \mathrm{~m}^{2}$. Käsittelyt on esitetty taulukossa 1. Varsinaisena viljelyn lopettamisvuonna 2009 ensimmäinen ruutu lannoitettiin ja siltä korjattiin helpisäilörehu. Myöhemmin kasvusto ruiskutettiin. Seuraavana vuonna edellisvuoden ruiskutettu helpi niitettiin, ja ruudulle kylvettiin Voitto-ohra.

Toista ruutua ei lannoitettu keväällä 2009, ja se ruiskutettiin heinäkuun alussa. Ruskettunut kasvusto niitettiin, ruutu jyrsittiin ja sille kylvettiin Iki-timotei. Seuraavana vuonna timoteistä korjattiin kaksi säilörehusatoa. Kolmas ruutu ruiskutettiin kahdesti vuonna 2009. Kuivettunut helpi korjattiin seuraavan vuoden toukokuussa, ja ruudulle kylvettiin ohra.

Neljäs ja viides ruutu käsiteltiin pelkästään mekaanisesti. Neljäs ruutu kynnettiin ja lisäksi jyrsittiin kahdesti vuonna 2009. Seuraavana vuonna ruutu jyrsittiin jälleen, ja siihen kylvettiin ohra. Viides ruutu kynnettiin ja äestettiin vuonna 2009 ja siihen kylvettiin heti ohra. Samoin seuraavana vuonna ruudulle kylvettiin ohra.

Kokeet havainnoitiin vuosina 2009 ja 2010 kerran viikossa kirjoittamalla ylös yleiskuva ruudusta, ruokohelpiversojen esiintyminen, muut havainnot sekä valokuvaamalla ruutu. Ruutuja ei viljelty vuonna 2011, mutta niitä havainnoitiin vielä noin kahden viikon välein. 
Taulukko 1. Koeruuduilla tehdyt viljelytoimenpiteet ja niiden ajankohdat. Kemiallisen torjunnan kohdalla on ilmoitettu suluissa tehoaineen, glyfosaatin, määrä hehtaaria kohti.

\begin{tabular}{|c|c|c|c|c|c|}
\hline Vuosi & Ruutu & Korjuu & Kemiallinen torjunta & Mekaaninen torjunta & Kylvö \\
\hline 2009 & 1 & Säilörehu 1.7 & Roundup Max (1,36 kg/ha) 14.8. & - & - \\
\hline 2010 & 1 & $\begin{array}{l}\text { Jäännöshelpi 15.5. } \\
\text { Ohran puinti 21.8. }\end{array}$ & - & Jyrsintä 24.5., äestys 28.5. & Ohra 28.5. \\
\hline 2009 & 2 & - & Roundup Max (1,36 kg/ha)7.7. & Jyrsintä 12.8. & Timotei 12.8 . \\
\hline 2010 & 2 & S-rehu 29.6. ja 4.8. & - & - & - \\
\hline 2009 & 3 & - & $\begin{array}{l}\text { Roundup Max(1,36 kg/ha)7.7.ja } \\
\text { uusintaruiskutus(1,36 kg/ha)14.8. }\end{array}$ & - & - \\
\hline 2010 & 3 & $\begin{array}{l}\text { Jäännöshelpi 15.5. } \\
\text { Ohran puinti 21.8. }\end{array}$ & - & Jyrsintä 24.5., äestys 28.5. & Ohra 28.5. \\
\hline 2009 & 4 & - & - & Kyntö 25.5., jyrs. 27.5., 14.7. & - \\
\hline 2010 & 4 & $\begin{array}{l}\text { Jäännöshelpi 15.5. } \\
\text { Ohran puinti 21.8. }\end{array}$ & - & Jyrsintä 24.5., äestys 28.5. & Ohra 28.5. \\
\hline 2009 & 5 & - & - & Kyntö 25.5., äestys 28.5. & Ohra 28.5. \\
\hline 2010 & 5 & - & - & Jyrsintä 24.5., äestys 28.5. & Ohra 28.5. \\
\hline
\end{tabular}

Viiden koeruudun lisäksi ruokohelven viljely lopetettiin kahdella muulla alueella (Taulukko 2). Toisella alueella (koealue 6) oli viljelty ruokohelpeä vuodesta 2004 lähtien. Kokeessa korjattiin vuonna 2010 alueelta kaksi säilörehusatoa, samana syksynä alue ruiskutettiin ja kynnettiin. Glyfosaattivalmistetta Rambo 360 S (Tukes 2011 a) käytettiin 5 litraa hehtaarille kiinnitteen kanssa. Valmisteen glyfosaattipitoisuus on $360 \mathrm{~g} / \mathrm{l}$.

Toisella alueella (koealue 7) oli ollut ruokohelven yksilöaineistokoe. Vuonna 2010 pellolle kylvettiin ruokohelven jälkeen ohra, mutta ruokohelpeä ei torjuttu missään vaiheessa kemiallisesti. Ruokohelpeä kasvoi ohran seassa runsaasti. Kasvusto ruiskutettiin, kun ohra oli tuleentunut, ja ruokohelven häviämistä seurattiin kolmella 16 neliömetrin alueella. Joka ruudulta laskettiin helpiversot neliömetrin alalta ennen ruiskutusta 2010 ja uudelleen elokuussa 2011. Glyfosaattivalmisteena oli Roundup Bio (Tukes 2011 b), jota käytettiin käyttöohjeen mukaisesti 3 litraa hehtaarille. Valmisteen glyfosaattipitoisuus on $360 \mathrm{~g} / \mathrm{l}$. Ennen puintia tapahtuvassa juolavehnän torjunnassa varoaika on 10 vrk. Ruiskutushetkellä on viljanjyvien kosteus oltava alle 30 \%. Käsiteltyjä olkia ei saa käyttää eläinten rehuksi.

Taulukko 2. Ruokohelven hävittäminen kemiallisesti kahden säilörehusadon jälkeen (ruutu 6) sekä ruiskuttamalla tuleentunut ohrakasvusto (ruutu 7). Viljely- ja torjuntatoimenpiteet ja niiden päivämäärät. Kemiallisen torjunnan kohdalla on ilmoitettu suluissa tehoaineen, glyfosaatin, määrä hehtaaria kohti.

\begin{tabular}{llll}
\hline Vuosi & Ruutu & Viljelytoimenpiteet & Kemiallinen ja mekaaninen torjunta \\
\hline 2009 & 6 & $\begin{array}{l}\text { Helven kevätkorjuu } \\
\text { Lannoitus 26.5. }\end{array}$ & \\
2010 & 6 & Helpisäilörehu 30.6. ja 2.8. & $\begin{array}{l}\text { Rambo 360 S (1,8 kg/ha) 9.9. } \\
\text { Syyskyntö 20.10. }\end{array}$ \\
& & Ruokohelven yksilöaineisto & Kyntö ja äestys \\
2009 & 7 & $\begin{array}{l}\text { Helven kevätkorjuu } \\
\text { Ohran kylvö }\end{array}$ & Roundup Bio (1,08 kg/ha) 12.8.
\end{tabular}

\section{Ruokohelven leviämiskoe}

MTT Sotkamon tutkimusasemalle perustettiin havaintokoe, jossa tutkittiin ruokohelven leviämistä viereiselle lohkolle. Ruokohelpipelto, jonka koko oli 15 aaria, oli kylvetty tutkimusasemalle vuonna 2004. Lajikkeena oli Palaton. Ruokohelpipellon vieressä oli kolme koelohkoa, joilla viljeltiin vuosina 
2008 - 2010 1) kevätviljaa, 2) nurmea ja 3) yksi lohko oli joutomaana. Vuonna 2011 lohkoja havainnoitiin noin kolmen viikon välein. Kevätviljalohko kynnettiin ja kylvettiin joka vuosi. Viljalle tehtiin normaalit viljelytoimenpiteet. Nurmilohkolta korjattiin sato kahdesti kasvukauden aikana ja lohkoa lannoitettiin. Joutomaa jyrsittiin kerran vuodessa.

Oletus oli, että ruokohelven juurakko ei leviä kevätviljapellolle, joka kynnetään vuosittain. Nurmeen juurakko voi levitä helpommin. Toisaalta nurmen sadonkorjuu saattaa hidastaa ruokohelven kasvua, sillä helpi ei kestä tiheitä niittoja. Joutomaalle leviäminen on esteettömintä.

\section{Ruokohelven kukinta ja siitepöly}

MTT Sotkamon tutkimusasemalla seurattiin kesällä 2010 ruokohelven kukintaa ja sen edistymistä. Ruokohelven virallisesta lajikekokeesta laskettiin Palaton-lajikkeen kukkivien röyhyjen lukumäärä kolmesta kohdasta koeruutua. Siitepölyä ei havainnoitu, mutta siitä etsittiin tietoa kirjallisuudesta.

\section{Tulokset ja niiden tarkastelu Ruokohelven hävittämiskoe}

Ensimmäisellä koeruudulla glyfosaattiruiskutus tehtiin hieman liian myöhään, ja kasvusto oli ehtinyt jo melko pitkäksi. Kasvusto kellastui ja muuttui ruiskutuksen jälkeen ruskeaksi, mutta korsissa oli vielä syksyllä havaittavissa vihreää. Vuonna 2010 kylvetty ohra orastui hyvin, ja kasvusto oli tasainen koko kasvukauden ajan. Ruudun yhdessä kulmassa kasvoi muutama ruokohelpi. Vuonna 2011 helpeä kasvoi ruudun reunoilla hieman.

Toisen ruudun kasvusto oli heinäkuun alussa 2009 ruiskutettaessa melko pitkää ja tulossa jo röyhylle. Timotein kylvö jyrsittyyn maahan onnistui hyvin. Timotei tuli pian oraalle ja kasvusto oli tiheä. Kaksi viikkoa timotein kylvön jälkeen ruudulla havaittiin kuitenkin helpiversoja. Vuonna 2010 kasvukauden alussa havaittiin muutamia helpiversoja, mutta ne hävisivät kasvavan timotein sekaan. Pian ensimmäisen ja myös toisen niiton jälkeen muutamia timotein korkuisia ruokohelpiä ympäri ruutua. Ruokohelpi ei hävinnyt täysin nurmen seasta, mutta nurmen toistuvat niitot heikensivät sitä. Vuonna 2011 ruudulla kasvoi vain muutamia helpiä.

Kolmannen ruudun ruiskutus viivästyi samoin kuin toisen ruudun. Viivästymisen voisi olettaa heikentävän ruiskutuksen tehoa, mutta kasvusto ruskettui täysin toisen ruiskutuksen jälkeen. Vuonna 2010 ohran kylvön jälkeen ruudun pinnalla oli kuivuneita ruokohelven juurakon palasia. Ohran seassa ei havaittu kesä aikana ruokohelven versoja. Kuitenkin vuonna 2011 helpiversoja oli jälleen näkyvissä.

Neljännen ruudun mekaaninen torjunta vuonna 2009 ei riittänyt hävittämään ruokohelpeä, jota kasvoi jyrsinnän jälkeen suhteellisen runsaasti. Toisen jyrsintäkerran jälkeen ruokohelven lisäksi ruudun valtasivat rikkakasvit. Vuonna 2010 kylvetyn ohran joukossa kasvoi kesäkuussa sekä ohran mittaisia että pieniä ja hentoja, noin $5 \mathrm{~cm}$ korkuisia ruokohelpiversoja. Ohran tullessa tähkälle ruokohelpi ei erottunut kasvuston seasta. Elokuussa ruudulla oli havaittavissa helpeä, mutta juolavehnä oli pahempi ongelma. Vuonna 2011 juolavehnää oli ruudulla todella paljon.

Viidennellä ruudulla ruokohelpi kasvoi ohraa korkeammaksi vuonna 2009. Elokuussa suhteellisen runsaana kasvava helpi erottui vihreänä tuleentuneen ohran joukosta. Kaksi viikkoa puinnin jälkeen ruokohelpeä kasvoi ruudulla. Seuraavana vuonna kesäkuun lopussa havaittiin pieniä helpiä, mutta ne hukkuivat myöhemmin ohrakasvuston sekaan. Juolavehnä muodostui neljännen ruudun tavoin ruokohelpeä pahemmaksi ongelmaksi tälläkin ruudulla. Neljännellä ja viidennellä ruudulla käytettiin mekaanisena torjuntana sekä kyntöä että jyrsintää, joista jyrsintä ei ilmeisesti ole kyntämisen veroinen torjuntakeino.

Koeruudulta 6 ruokohelpi hävisi tehokkaasti vuonna 2010. Ruudulla ei havaittu ruokohelpeä keskikesään 2011 mennessä. Tämän jälkeen lohko kynnettiin. Koealueelta 7 ruokohelpi näytti häviävän ruiskutuksen jälkeen. Ennen ruiskutusta helpiversoja oli keskimäärin $14,7 \mathrm{kpl} / \mathrm{m}^{2}$. Seuraavana vuonna 2011 versoja ei näyttänyt alkukesällä olevan ollenkaan, mutta elokuussa niitä oli keskimäärin $4 \mathrm{kpl} / \mathrm{m}^{2}$.

Parhaimmiksi hävittämiskeinoiksi todettiin glyfosaattiruiskutus yksi tai kaksi kertaa kasvukaudessa sekä seuraavana vuonna hyvä muokkaus ja kevätviljan kylvö. Kaksi ruiskutuskertaa ei osoittautunut tehokkaammaksi torjuntakeinoksi kuin yksi ruiskutuskerta. Tässä kokeessa helpiversoja havaittiin kahdesti ruiskutetulla ruudulla jopa enemmän kuin yhdesti ruiskutetulla. Tältä ruudulta ei saatu yhtään satoa. Ruutu 6:n käsittely vaikutti parhaalta torjuntatavalta, koska kasvustosta saatiin kaksi 
satoa, ja samana kasvukautena ehdittiin vielä ruiskuttaa ja kyntää ruutu. Myös hävitystulos oli lupaavin. Tosin ruutua seurattiin vain yhtenä vuonna helven hävittämisen jälkeen.

Mekaaninen torjunta ei riittänyt ruokohelven hävittämiseen. Huomionarvoista oli, että juolavehnä oli hävittämistä seuraavina vuosina näillä ruuduilla huomattavasti hankalampi rikkakasvi kuin ruokohelpi.

\section{Ruokohelven leviämiskoe}

Ohralohkolla kasvoi kaikkina vuosina hieman ruokohelpeä. Vuonna 2009 havaittiin pieniä ja hentoja ruokohelven oraita, ilmeisesti siemenestä levinneitä. Ne hävisivät kasvavan ohran sekaan, mutta puinnin jälkeen muutamia helpiä paljastui ympäri lohkoa. Vuonna 2010 ohra kärsi märkyydestä ja oli kitukasvuista. Täysikasvuinen ja vahvan juurakon omaava ruokohelpi ei kärsi helposti liiasta märkyydestä, mutta taimet eivät menesty liian märässä (Tu 2004). Ruudulla kasvoi muutamia helpiä, mutta oraita ei ollut märässä kohdassa. Ruokohelvet olivat selvästi keskittyneet ruudun reunoille. Niitä kasvoi sekä lähellä ohran ja ruokohelpipellon rajaa että ohraruudun toisella laidalla ja ruudun päissä. Aivan ohraruudun ja ruokohelpipellon raja oli kynnetty teräväksi, eikä siinä esiintynyt ruokohelpiä. Reunoilla kasvaneet helvet olivat ilmeisesti levinneet siemenistä. Koeruudun reunat olivat tarjonneet niille sopivan itämisalustan esimerkiksi muokkauksen yhteydessä, mutta ohrakasvuston keskellä ne eivät niinkään olleet itäneet.

Nurmen perustamisvuonna 2008 ruokohelpiä oli itänyt jonkin verran nurmen seassa. Vuonna 2009 nurmen niitto oli ilmeisesti heikentänyt helpiä niin, että ne eivät ole voineet kasvattaa elinvoimaista juuristoa. Siemenistä leviäminen on todennäköisesti ollut vähäistä perustamisvuoden jälkeen, sillä ruokohelven siemen tarvitsee itääkseen ja menestyäkseen hyvän itämisalustan, eikä se kestä varjostusta (Tu 2004). Kesän 2010 aikana ohraruudulla kasvoi vain muutamia ruokohelpiä. Nurmen ja ruokohelven raja oli edelleen selvä, eikä kasvullista lisääntymistä ollut havaittavissa. Ennemminkin timoteitä oli levinnyt ruokohelpipellon puolelle. Ruokohelven kasvullista leviämistä nurmelle on oletettavasti estänyt nurmen niitto kahdesti kasvukaudessa.

Kolmesta lohkosta joutomaalohkolla oli vuonna 2009 eniten ruokohelpeä. Helpi oli keskittynyt lohkon raja-alueelle. Tosin syksyllä tiheä rikkakasvusto oli tukahduttanut myös ruokohelven kasvua. Joutomaalle alkoi kasvaa kesän 2010 aikana rikkakasveja, kuten pihasauniota, pelto-ohdaketta ja peltovalvattia. Rikkakasveja ei ollut yhtä paljon kuin edellisenä vuonna, mutta jostain syystä vuonna 2010 joutomaalohkolla kasvoi vähemmän ruokohelpeä kuin nurmi- ja ohralohkoilla. Joutomaan ja ruokohelven raja oli terävä. Keväinen muokkaus oli oletettavasti heikentänyt helpeä niin paljon, ettei se kyennyt kasvamaan vapaasta kasvutilasta huolimatta. Joutomaan laidalla oli havaittavissa sama ilmiö kuin ohralohkon reunalla: helpeä kasvoi lohkon toisella reunalla, kauimpana helpipellosta. Ilmeisesti reuna oli muokattu matalaan tai se tarjosi muuten hyvän itämisalustan ruokohelven siemenille.

\section{Ruokohelven kukinta ja siitepöly}

Ruokohelven kukinta alkaa suunnilleen 65 päivän kuluttua kasvukauden alusta. Kukinnan kesto vaihtelee ruokohelvellä lajikkeittain, mutta luonnonhelpeen verrattuna kukkimisaika on noin kaksi päivää lyhyempi (Sahramaa \& Jauhiainen 2003). MTT Sotkamon tutkimusasemalla ruokohelven kukinta alkoi 9.7.2010 ja päättyi 22.7.2010, joten se kesti 14 päivää. Kuvassa 1 on esitetty kukkivien röyhyjen osuus kaikista röyhyistä neliömetrillä. Kuvaajassa ovat sekä kaikki kolmen neliötä että niiden keskiarvo. Röyhyistä yli puolet kukki noin viikon ajan Sotkamossa kesällä 2010. 


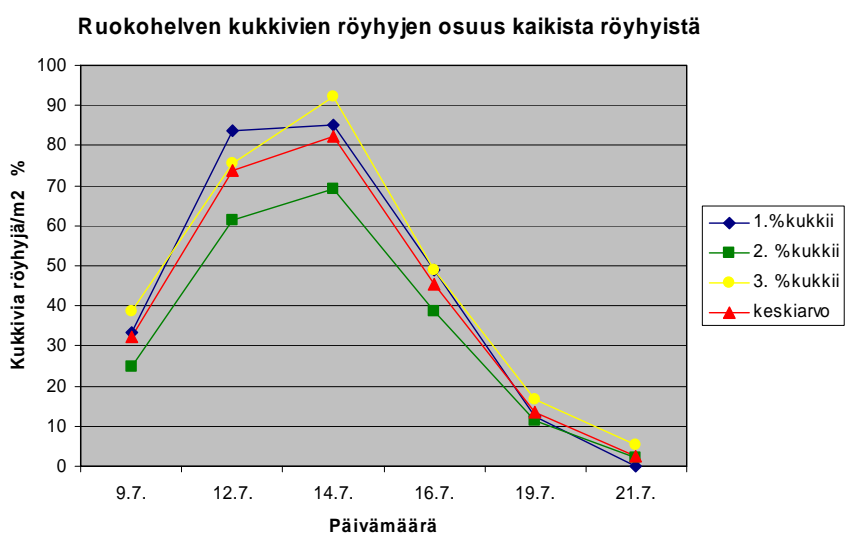

Kuva 1. Ruokohelven kukkivien röyhyjen osuus kaikista röyhyistä neliömetrillä (Nikkari 2010).

Ruokohelpi on ristisiittoinen ja tuulipölytteinen heinäkasvi. Siitepölyä on paljon, ja näin ollen ruokohelpi on merkittävä paikallinen allergian aiheuttaja (Antineau 1998). Siitepölyn leviämisestä ei juuri ollut saatavilla kirjallisuudesta tutkimustietoa.

Timotei (Phleum pratense ssp. pratense L) on myös monivuotinen ja tuulipölytteinen kasvi. Sen siitepöly on allergeeni, ja siitepölyn leviämistä on tutkittu ainakin Yhdysvalloissa. Tutkimuksessa timoteit kukkivat keskimäärin 17 päivää, ja eniten siitepölyä irtosi aamuisin. Tutkimuksessa pääteltiin, että siitepölyn lähteen sijainti yhdessä kukkimisen aikaisten sääolojen kanssa vaikuttavat eniten siitepölyn leviämiseen. Isommalta pellolta leviää enemmän ja myös kauemmas siitepölyä kuin pieniltä koealoilta. Siitepölyhiukkasten koolla tai muilla ominaisuuksilla ei todettu olevan kovin suurta vaikutusta siitepölyn leviämiseen. Tästä voidaan päätellä, että tulokset ovat sovellettavissa myös muiden vastaavien kasvien siitepölyn leviämiseen (Raynor ym. 1971)

\section{Johtopäätökset}

Vahvan juurakkonsa ansiosta ruokohelpi kestää hyvin muokkausta ja viljelyn lopettaminen on tehtävä huolella. Ruokohelpi suositellaan hävitettäväksi glyfosaattivalmisteella, kun odelma on $30-60 \mathrm{~cm}$ pitkää. Glyfosaatin käyttömäärä ja -tapa on sama kuin juolavehnän torjunnassa. Kasvusto kynnetään myöhään syksyllä. Kahtena seuraavana vuonna suositellaan kevätkylvöistä kasvia, kuten kevätviljaa, ja syyskyntöä. (Pahkala ym. 2005)

Ruiskutuskaan ei hävittänyt tässä tutkimuksessa helpeä täysin, vaikka aluksi näytti siltä. Kasvusto oli tosin pidempää kuin suositeltu $30-60 \mathrm{~cm}$. Ilmeisesti glyfosaatti ei kulkeutunut syvemmällä oleviin juurakon osiin, ja niistä kasvoi myöhemmin versoja. Kovin runsasta versominen ei kuitenkaan ollut, ja vuosittainen kyntö todennäköisesti pitää kasvin kurissa. Paras tulos saavutettiin, kun kasvustosta otettiin kaksi rehusatoa, se ruiskutettiin ja kynnettiin samana vuonna.

Myös niitto heikentää ruokohelpeä, eikä helpeä voi pitää tämän tutkimuksen perusteella haitallisena nurmen seassa. Rehukasvina siitä ei ole mainittavaa haittaa, vaikka sitä nurmen joukossa esiintyisikin. Mielenkiintoista oli, että juolavehnästä tuli mekaanisesti torjutuilla ruuduilla huomattavasti pahempi rikkakasvi kuin ruokohelvestä.

Ruokohelpi lisääntyy sekä vahvan juurakkonsa että siementen avulla. Juurakon avulla helpi ei kuitenkaan levinnyt pellon ulkopuolelle, kun viereisiä peltoja viljeltiin ja muokattiin. Ruokohelven siemenet alkoivat itää, kun olosuhteet esimerkiksi muokkauksen ansiosta olivat sopivat. Sen sijaan olemassa olevassa nurmessa ruokohelven siemen ei ilmeisesti idä elinkelpoiseksi versoksi.

Siitepölyn haitoista ei ole saatavilla suoraan tutkimustietoa. Timotein siitepölyn leviämistutkimuksen tuloksia soveltamalla ruokohelven siitepölyä ei voi pitää timotein siitepölyä pahempana allergeenina. Siitä saattaa olla kuitenkin enemmän haittaa kuin timoteistä, koska ruokohelpeä ei korjata kukinnan aikana, vaan siitepölyä leviää kukinnan loppuun saakka. Tämän osalta ruokohelpeä voi verrata tuulipölytteiseen rukiiseen (Secale cereale). Rukiin siitepölyn haitoista ei tiettävästi ole tehty tutkimusta. 


\section{Kirjallisuus}

Antineau, C. J. 1998. Biology and management of reed canary grass and implications for ecological restoration. Washington State Department of Transportation. http://ser.org/sernw/pdf/RCG_BIO_MGT.pdf.

Apfelbaum, S. I. \& Sams, C. E. 1987. Ecology and control of reed canary grass (Phalaris arundinacea L.). Natural Areas Journal 7(2):69-74.

Hakkarainen, J. 1998. Ruokohelpiviljelyn mahdollisuudet turvetuotantoalueilla ja käytännön viljelyksillä. Julkaisussa: Riitta Salo (toim.) Ruokohelpiseminaari, biomassan tuotanto pelloilla ja turvesoilla sekä käyttö energian tuotantoon, Oulunsalo 29.9.1997. Maatalouden tutkimuskeskus 39.

Nikkari, S. 2010. Ruokohelven viljely ja sen riskit. Harjoitteluraportti vuonna 2010 MTT Sotkamossa.

Pahkala, K. \& Mela, T. 2000. Ruokohelven viljelymenetelmät. Julkaisussa: Riitta Salo (toim.) Biomassan tuottaminen kuidun ja energian raaka-aineeksi. Tutkimuksen loppuraportti, osa I. Ruokohelven jalostus ja viljely. Maatalouden tutkimuskeskus, Jokioinen. Maatalouden tutkimuskeskuksen julkaisuja, Sarja A 84.

Pahkala, K., Hakala, K., Kontturi, M. \& Niemeläinen, O. 2009. Peltobiomassat globaalina energialähteenä. Maa- ja elintarviketalous137. Maa- ja elintarviketalouden tutkimuskeskus. MTT 31600 Jokioinen. 53 s. www.mtt.fi/met/pdf/met137.pdf

Pahkala, K., Isolahti, M., Partala, A., Suokannas, A., Kirkkari, A-M., Peltonen, M., Sahramaa, M., Lindh, T., Paappanen, T., Kallio, E. \& Flyktman, M. 2005. Ruokohelven viljely ja korjuu energian tuotantoa varten. 2. korjattu painos. Maa- ja elintarviketalouden tutkimuskeskus. $31 \mathrm{~s}$.

Raynor, G. S., Ogden, E. C. \& Haynes, J. V. 1971. Dispersion and deposition of timothy pollen from experimental sources. Agricultural Meteorology ) (1971/1972) 347-366.

Sironen, P. 2011. Suullinen tiedonanto 28.11.2011.

Tike 2007. Käytettävissä oleva maatalousmaa vuonna 2007. MMM tietopalvelukeskus. 14.12.2007. $\underline{\text { http://www.matilda.fi }}$

Tike 2011. Käytössä oleva maatalousmaa vuonna 2011 - ennakkotiedot 21.6.2011. MMM:n tietopalvelukeskus. 21.6.2011. http://www.matilda.fi

Tu, M. 2004. Reed Canary Grass (Phalaris arundinacea L.) Control \& Management in the Pacific Northwest. The Nature Conservancy, Oregon Field Office. http://www.invasive.org/gist/moredocs/phaaru01.pdf.

Tukes 2011 a. Turvallisuus- ja kemikaaliviraston torjunta-ainerekisteri. Rambo 360 S myyntipäällyksen teksti. https://kasvinsuojeluaineet.tukes.fi/Download/1902Rambo360S.pdf

Tukes 2011 b. Turvallisuus- ja kemikaaliviraston torjunta-ainerekisteri. Roundup Bio myyntipäällyksen teksti. https://kasvinsuojeluaineet.tukes.fi/Download/1722RoundupBio.pdf

Tukes 2011 c. Turvallisuus- ja kemikaaliviraston torjunta-ainerekisteri. Roundup Max myyntipäällyksen teksti. https://kasvinsuojeluaineet.tukes.fi/Download/1910RoundupMax.pdf

Virkkunen, E., Hoppula, K., Reinikainen, O., Kauppila, R., Kemppainen, J. \& Järvelin, V. 2010. Perustamislannoitus antaa potkua ruokohelvelle. Julkaisussa: Maataloustieteen Päivät 2010 [verkkojulkaisu]. Suomen Maataloustieteellisen Seuran julkaisuja no 26. Toim. Anneli Hopponen. Julkaistu 11.1.2010. Saatavilla Internetissä http://www.smts.fi Perustamislannoitus antaa potkua ruokohelvelle. ISBN 978-951-9041-54-4. 